\title{
ESTUDO RETROSPECTIVO DAS NEOPLASIAS DIAGNOSTICADAS EM ANIMAIS SELVAGENS PELO SERVIÇO DE PATOLOGIA DO HOSPITAL VETERINÁRIO DA UFPR ENTRE 1974 E 1996 \\ PEDRO RIBAS WERNER ${ }^{1}$, MARCIO CHIQUITO ${ }^{2}$, JOSÉ RICARDO PACHALY ${ }^{3}$
}

${ }^{1}$ Professor de Patologia Animal, Universidade Paranaense - UNIPAR, Umuarama - PR. ${ }^{2}$ Mestrando do Curso de PósGraduação em Ciências Veterinárias da Universidade Federal do Paraná. ${ }^{3}$ Professor de Clínica Médica de Pequenos Animais e Odontologia Veterinária, Universidade Paranaense - UNIPAR, Umuarama - PR.

Nos últimos anos, a clínica de animais selvagens vem assumindo uma importância cada vez maior. Em vista disso, torna-se necessário conhecer melhor os padrões de doenças ocorridas nesses animais. O presente estudo foi elaborado com dados dos arquivos do Serviço de Patologia do Hospital Veterinário da Universidade Federal do Paraná. Entre abril de 1974 e março de 1996, o Serviço de Patologia do Hospital Veterinário da Universidade Federal do Paraná diagnosticou 970 casos de neoplasias em animais, sendo 28 casos $(2,89 \%)$ em animais selvagens. Estas neoplasias acometeram seis hamsters, quatro camundongos, dois canários, dois coelhos, dois papagaios, dois periquitos australianos, uma cobaia. um macaco do gênero Cebus, uma cutia, uma marreca irerê, um puma, um lóris negro, um guará, um sabiá e um leão (portador de neoplasias de dois diferentes tipos histológicos). Dezessete casos $(60,7 \%)$ eram de neoplasias malignas: seis linfossarcomas, três carcinomas espinocelulares, três carcinomas indiferenciados, um fibrossarcoma, um hemangiossarcoma, um sarcoma indiferenciado, um seminoma, um adenocarcinoma de glândula sebácea e um adenocarcinoma (sem especificação). Além disso, registraram-se dois $(7,14 \%)$ carcinomas basocelulares, considerados mais como localmente agressivos do que como malignos. As neoplasias benignas somam nove casos (32,14\%): dois hemangiomas, dois lipomas, dois fibromas, uma adenoma hepatocelular, um papiloma e um tricoepitelioma. Excluiu-se desta pesquisa um caso de melanocarcinoma ocorrido no pescoço de um pássaro não identificado. 